\title{
Research Paper: Effect of Pilates Exercise on Fear of Falling in Iranian Elderly Women
}

\author{
Mahsa Badiei ${ }^{1}$, Farahnaz Mohammadi Shahboulaghi ${ }^{1,2 *}$, Mohammadali Hosseini ${ }^{3}$, Mahdi Noroozi $^{4}$, Shima Nazari $^{5}$ \\ 1. Department of Nursing, University of Social Welfare and Rehabilitation Sciences, Tehran, Iran. \\ 2. Iranian Research Center on Aging, University of Social Welfare and Rehabilitation Sciences, Tehran, Iran. \\ 3. Department of Nursing, University of Social Welfare and Rehabilitation Sciences, Tehran, Iran. \\ 4. Social Determinates of Health Research Center, University of Social Welfare and Rehabilitation Sciences, Tehran, Iran \\ 5. Department of Nursing Management, School of Nursing and Midwifery, Tehran University of Medical Sciences, Tehran, Iran.
}

Article info:

Received: 16 Jun. 2017

Accepted: 11 Sep. 2017

\section{Keywords:}

Pilates, Fear, Fall, Aged, Fear of Falling (FOF)
Citation: Badiei M, Mohammadi Shahboulaghi F, Hosseini M, Noroozi M, Nazari Sh. Effect of Pilates Exercise on Fear of Falling in Iranian Elderly Women. Iranian Rehabilitation Journal. 2017; 15(4):389-398. https://doi.org/10.29252/NRIP.IRJ.15.4.389

https://doi.org/10.29252/NRIP.IRJ.15.4.389 


\section{Introduction}

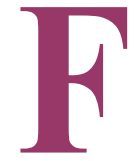

alling is one of the most common and problematic issues among the elderly [1]. On an average, more than a quarter of the elderly population is likely to experience a fall once in a year [2]. Owing to its prevalence and severity, the World Health Organization has categorized falls as the third leading cause of chronic disability [3]. Fear of Falling (FOF) has been categorized as a crucial psychological factor that often leads to falling [4].

Principally, FOF is a psychological state which increases physical weakness and reduces the levels of physical activity in older adults. Furthermore, its prevalence among the elderly population is substantially high. Many studies have reported that an average of $21-85 \%$ of the elderly population has FOF [5-8]. The various risk factors that have been identified to be associated with FOF are previous history of falling, impaired gait, imbalance, unsteadiness, muscle weakness and limitation of daily tasks $[9,10]$. It is important to consider that presence of FOF in the elderly can reduce their ability to perform daily activities, which further reduces their mobility levels and thus, overall Quality of Life (QoL).

This, in turn, is known to decrease physical strength and robustness and increase the risk of actual falling, depression and isolation [10-12]. The "FOF" problem has been a major concern not only for the elderly, but also for their caretakers, families and health care providers. This can be understood from the fact that a simple psychological fear can lead to the occurrence of a number of health discrepancies and thus necessitate increased dependence on health care services $[13,14]$.

The present article is centered upon the above mentioned factors as observed in the elderly population of Iran. It has been observed that aging and its implications vary greatly between elderly Iranian women and men. Previous studies indicated that Iranian women follow different strategies to achieve optimal health due to which they are more likely to experience healthy aging in a natural way [15]. Furthermore, it has also been observed that they perceive optimal mental health through physical health. Interestingly, "seeking comfort" is the most basic psycho-social process that they follow to maintain their health $[16,17]$. However, the prevalence of FOF in elderly women was observed to be higher than in men [18].

Once medical experts identified FOF as the root cause of most clinical presentations of falls in elderly population, they started studying and finding out possible psy- chological as well as medical interventions that can help in preventing it. Some of the most commonly adopted interventions for this purpose include, usage of hip protectors, educating the geriatric population regarding the causes and implications of FOF, teaching and encouraging them to follow exercise routines and improve their socialization skills [19-21].

Studies have also already shown that learning different types of sports and balance training viz. Tai Chi, yoga and strength training are helpful in reducing the levels of FOF and thus minimizes the chances of falling [21-25], but others also have no significant relationship [26, 27]. Though it is proposed that sports can imply significant beneficial effects in the elderly population, there is still no agreement on the individualistic impacts of different sports exercises on specific traits of physical abilities of the elderly. Pilates Exercise is one of the very few sporting techniques the effects of which have been studied by sports and rehabilitation researchers [28, 29].

Among the various sports, Pilates exercise is a kind of cognitive and motion training program that can be used as a complementary therapy so as to augment the process of improving strength, concentration, flexibility, muscle control, postural stability and breathing [30-32]. In addition, Pilates exercise has also shown to have beneficial effects in reducing FOF [30, 31, 33-36]. However, exclusive studies that prove the same in the elderly population, especially on the fall and the FOF among older adults are lacking. The present study was thus designed to study the impact of Pilates exercises on FOF in elderly women. The study was conducted with the aim that validation of beneficial effects of Pilates exercises, which are essentially highly safe and low-cost alternative exercise routines, can help in its propagation as a complementary therapeutic method for the treatment of FOF in the elderly community.

\section{Methods}

\section{Study setting and participants}

The present study was a randomized control trial, which investigated the effects of 8-week Pilates training on FOF of elderly women. The study was conducted between September-November, 2016. Participants included 44 elderly women who were chosen out of the 120 elderly women who were referred to the day care center of Kahrizak sanatorium (Alborz Province) via the convenient sampling method. Inclusion criteria were- age between 60 to 80 years, willingness to join the study and signing the consent form, having medical approval that 
certifies the person's ability to participate in physical activity and exercise routines, no history of hospitalization in the past 3 months as well as ability and availability to attend at least $80 \%$ of the Pilates exercise sessions.

Exclusion criteria were applying mobility-aids, suffering from any physical and mental ailments that can prevent them from continuing the exercise program and attending other concurring coherent exercise programs other than the routine workouts of the sanatorium. The selected participants signed written informed consent at the beginning of the intervention. Participants were allocated randomly into two groups (intervention group and control group) of 22 women each. Both groups continued with their routine exercises of the sanatorium. In addition, the intervention group practiced Pilates exercises (hourly sessions, three times per week for 8 weeks) under the supervision of a trained coach.

\section{Data collection}

Demographic data was collected with the help of a questionnaire that helped in acquiring information regarding the age, marital status, education, height, weight, medical history, medicine intake, history of falling, age of menopause, smoking, past sport activities and presence of pain in different organs. The Fall Efficacy Scale - International (FES-I) was used to evaluate the outcomes of the exercise routine (possibility of falling). This questionnaire consisted of 16 questions that were specifically designed to evaluate the physical, social and functional aspects associated with the concern of falling.

The level of concern was measured on the Likert scale of 1 to 4 , where $1=$ not at all concerned and 4=extremely concerned), with a score that can vary from 16 to 64 . This questionnaire has already been validated in several countries as a reliable method of measuring FOF in elderly population [37]. The Persian version of FES-I that has already been approved by Khajavi $(\alpha=0.98)$ for its validity and reliability, was used in the current study [38]. Cronbach's alpha of 0.93 in the current research was gained. This Questionnaire was completed in two stages (before and after intervention).

\section{Intervention}

Pilates exercise protocol of this study was derived from the protocol of Pérez [39]. These exercises were performed in the classical way on mattresses, including three parts of warm up with Pilates breathing and stretching exercises followed by the main workout session and finally cooling down. Exercises were divided into two parts; the first week consisted of primary level pre-Pilates exercises (Table 1), and for the next seven weeks included core interventional exercising. The exercise protocol was further amended by adding new intermediate-level exercises that were decided on the basis of individualistic ability and readiness (Table 2). It was ensured that the participants reported nod is comfort throughout the period of intervention. The control group continued routine workouts of the sanatorium (included stretching training) as usual.

\section{Data analysis}

Descriptive Statistics used to summarize the participants' base-line characteristics included mean and Standard Deviation (SD) for continuous variable. Statistical tests, like the independent T-test and Chi-square test, were used for comparing the difference in demographic variables between the intervention and control groups. In order to compare the possible effects of Pilates on Fear of Falling (FOF), independent t-test and Paired samples t-test were used. In addition, Kolmogorov-Smirnov Test was applied to evaluate the normal distribution of variables. ANCOVA was used to assess the impact of the intervention while controlling the co-variant effects of age and the pre-test. Assumptions of normal distribution of scores and homogeneity of variance were evaluated. SPSS version 16 was used for data analysis.

\section{Ethical approval}

The study was approved by the Ethics Committee of the University of Social Welfare and Rehabilitation Sciences (IR.USWR.REC.1395.352) and the Register Center for Clinical Trials of Iran (IRCT: 2017010431767N1). The purpose of the study was fully explained to the participants and it was ensured that all of them provided written personal consent. The consent form also ensured that the collected data of questionnaires will remain confidential.

\section{Results}

Forty-four elderly women who visited the Kahrizak daycare center, Alborz Province, participated in the study. All the participants completed the study protocol (22 allocated to intervention group and 22 to control group) (Figure 1). Their ages ranged between 60 to 80 years, with a mean age of $68 \pm 5.9$ for the intervention group and $71 \pm 4.1$ for the control group. It was noted that there was a significant difference between them $(\mathrm{P}=0.01)$. However, both groups were found to be similar in terms of Body Mass Index (BMI). Chi-Square test results showed no significant difference between the two groups in terms 




Dranlan Rkhabillutton Dourna

Figure 1. Diagram of randomized control trial of effect of pilates exercise on fear of falling in elderly women

of education ( $\mathrm{P}=0.2)$, marital status $(\mathrm{P}=0.2)$, living status $(\mathrm{P}=0.7)$, past medical history $(\mathrm{P}>0.05)$, medicine intake $(\mathrm{P}=0.2)$, presence of pain in the body organs $(\mathrm{P}>0.05)$, history of falling $(\mathrm{P}=0.5)$, number of falls during past year $(\mathrm{P}=0.4)$ and history of past exercises $(\mathrm{P}=0.6)$ (Table 3$)$.

The results indicated that there was no significant difference between the FES-I scores in the intervention and control group in the beginning of the intervention $(\mathrm{P}=0.6)$. However, a significant difference was observed in the values after the completion of the Pilates exercise intervention $(\mathrm{P}<0.001)$ (Table 4). Also, mean difference of FOF between pre-test and post-test scores in the control group was [1] score while the Pilates group had [10] scores $(\mathrm{P}<0.001)$ (Table 4).

Table 1. Planning classes in the first weeks: PM for beginner client

\begin{tabular}{|c|c|c|c|c|}
\hline $\begin{array}{l}\text { Prepilates Exercise } \\
\text { (Lying Down) }\end{array}$ & $\begin{array}{l}\text { Prepilates Exercise } \\
\text { (Sitting Up) }\end{array}$ & Beginner Mat & Wall Series & $\begin{array}{l}\text { Series With Weight } \\
(1 \mathrm{~kg})\end{array}$ \\
\hline $\begin{array}{l}\text { Exploring the power } \\
\text { house }\end{array}$ & $\begin{array}{l}\text { Towering above the } \\
\text { hips }\end{array}$ & The hundred & Arm circle & Arm forward 90 \\
\hline $\begin{array}{l}\text { Pushing the navel } \\
\text { toward the spine }\end{array}$ & Lifting the knee & Rolling up & Rolling down & Arm to the side 90 \\
\hline $\begin{array}{l}\text { Pushing the column } \\
\text { toward the mat }\end{array}$ & $\begin{array}{l}\text { Raising and lowering } \\
\text { the shoulders }\end{array}$ & Leg circle & Sitting on the chair & $\begin{array}{c}\text { Flexion of the forearm } \\
\text { standing }\end{array}$ \\
\hline $\begin{array}{l}\text { Stretching the neck-chin } \\
\text { leading toward the chest }\end{array}$ & $\begin{array}{l}\text { Shoulder circles from } \\
\text { one side to the other }\end{array}$ & Single leg stretching & & \\
\hline \multirow[t]{3}{*}{ Rolling down } & $\begin{array}{l}\text { Looking toward the } \\
\text { navel }\end{array}$ & Double leg stretching & & \\
\hline & $\begin{array}{l}\text { Bringing the ear to the } \\
\text { shoulder }\end{array}$ & $\begin{array}{l}\text { Spine stretching } \\
\text { forward }\end{array}$ & & \\
\hline & Half circle & & & \\
\hline
\end{tabular}

Source: Perez et al. (2014) [39]

Mrantan Rehabolltortion Journa 
Table 2. Planning classes in the next seven weeks of intervention: PM for intermediate client

\begin{tabular}{|c|c|}
\hline Level: Intermediate Mat & Repetition \\
\hline The hundred & 10 sets for 10 repetition \\
\hline Rolling up & 3 \\
\hline Leg circle & 5 each way \\
\hline Rolling like a ball & 6 \\
\hline Single leg stretching & 6 \\
\hline Double leg stretching & 5 \\
\hline Single straight leg stretching & 5 set \\
\hline Double straight leg stretching & 5 \\
\hline Criss-Crossing & 5 set \\
\hline Spine stretching forward & 3 \\
\hline Open leg rocker & 6 \\
\hline Corkscrew & 3 set \\
\hline Saw & 3 set \\
\hline Neck circle & 1 each way \\
\hline Single leg kicking & 5 \\
\hline Double leg kicking & 2 set \\
\hline Neck pulling & 3 \\
\hline Side kicking series: front-behind & 5 \\
\hline Side kicking series: up-down & 3 \\
\hline Small circle & 5 \\
\hline Teaser 1 & 3 \\
\hline Sealing & 6 \\
\hline
\end{tabular}

To illustrate the exact effects of the intervention on FOF by controlling age and pre-test score, ANCOVA test was applied. Data presented in Table 5 indicates that Pilates interventions led to a significant difference in FOF levels between the intervention and control group. Considering the pre-test scores and age as a co-variant variable $(\mathrm{P}<0.001)$ and (Adjusted R Squared $=0.89)$, and the intervention effect size was found to be 0.89 (Table 5). In other words, 89 percent of variance of post-test scores (FOF) was due to the Pilates intervention.

\section{Discussion}

This study was designed to investigate the possible effect so fan 8-weeks long Pilates exercise program on the levels of FOF among elderly women of Kahrizak sanatorium daycare center. The results showed that adding Pilates exercise to their routine daily workout sat the sanatorium could significantly decrease FOF. It has already been established that FOF is a major health problem among the elderly living in communities and it is responsible for increasing the risk and chances of actually falling down. Participants receiving the Pilates intervention showed better results than the control group who continued with the routine daily workouts of the Sanitarium only. These findings were aligned with several previously conducted studies on the same topic viz. Arantes (2015), Olsen et al. (2014), Kendrick et al. (2014) [21-23].

Conventionally, decrease in muscle strength, balance, flexibility and gait alteration are associated with an increase in FOF levels. Hence, effectiveness of Pilates exercise in decreasing FOF can be directly linked with improvement in these parameters $[9,10]$. Trombetti et al. (2016) showed that declining muscle mass, strength 
Table 3. Demographic characteristics of participants at baseline for both groups

\begin{tabular}{|c|c|c|c|c|}
\hline \multicolumn{2}{|c|}{ Variable } & \multirow{2}{*}{$\begin{array}{c}\text { Pilates Group } \\
68(5.9)\end{array}$} & \multirow{2}{*}{$\begin{array}{c}\text { Control Group } \\
71(4.1)\end{array}$} & \multirow{2}{*}{$\begin{array}{c}\mathbf{P} \\
0.01\end{array}$} \\
\hline & Age, mean(SD), y & & & \\
\hline & $\mathrm{BMI}$, mean(SD), kg.m² & $30.63(2.9)$ & $28.68(5.2)$ & 0.1 \\
\hline & Age of menopause, mean(SD), y & $48(6.61)$ & $45(10.9)$ & 0.1 \\
\hline & Falls in the past year, Mean(SD), $n$ & $1.54(1.79)$ & $2(2.4)$ & 0.4 \\
\hline & Exercise length, mean(SD), y & $2.3(0.9)$ & $2.4(1.2)$ & 0.6 \\
\hline \multirow{3}{*}{ Educational status, n (\%) } & Illiterate & $11(50)$ & $11(50)$ & \multirow{3}{*}{0.2} \\
\hline & Elementary & $5(22.7)$ & $7(31.8)$ & \\
\hline & Junior and diploma & $6(27.3)$ & $4(18.2)$ & \\
\hline \multirow{2}{*}{ Marital status, n (\%) } & Married & $11(50)$ & $10(45.5)$ & \multirow{2}{*}{0.1} \\
\hline & Divorced and widowed & $11(50)$ & $12(54.5)$ & \\
\hline \multirow[b]{2}{*}{ History of falls, $n(\%)$} & Yes & $15(68.2)$ & $17(77.3)$ & \multirow[b]{2}{*}{0.5} \\
\hline & No & $7(31.8)$ & $5(22.7)$ & \\
\hline \multirow{3}{*}{ Living status, $\mathrm{n}(\%)$} & With husband & $11(50)$ & $9(40.9)$ & \multirow{3}{*}{0.7} \\
\hline & Alone & $6(27.3)$ & $6(27.3)$ & \\
\hline & With children (s) & $5(22.7)$ & $7(31.8)$ & \\
\hline \multirow{6}{*}{ Medical history, n (\%) } & Cardiac disorders & $4(18.2)$ & $2(9.1)$ & 0.4 \\
\hline & Hypertension & $16(72.7)$ & $15(68.2)$ & 0.7 \\
\hline & Muscle-skeletal disorder & $17(77.3)$ & 20(90.9) & 0.2 \\
\hline & Metabolic disorders & $9(40.9)$ & $13(59.1)$ & 0.2 \\
\hline & Respiratory disorders & $1(4.5)$ & $2(9.1)$ & 0.5 \\
\hline & Visual-auditory disorder & $12(54.5)$ & $15(68.2)$ & 0.3 \\
\hline \multirow{5}{*}{ Drugs intake $n(\%)$} & Cardiovascular drugs & $18(81.8)$ & $15(68.2)$ & 0.3 \\
\hline & Blood sugar control drugs & $8(36.4)$ & $8(36.4)$ & 1 \\
\hline & Analgesia and anti-depression & $6(27.3)$ & $4(18.2)$ & 0.4 \\
\hline & Fat controlling drugs & $7(31.8)$ & $8(36.4)$ & 0.7 \\
\hline & Thyroid drugs & $3(13.6)$ & $1(4.5)$ & 0.2 \\
\hline \multirow{3}{*}{$\begin{array}{l}\text { Presence of Pain in differ- } \\
\text { ent organs } n(\%)\end{array}$} & Low back & $8(36.4)$ & $13(59.1)$ & 0.1 \\
\hline & Knee & $16(72.7)$ & $17(77.3)$ & 0.7 \\
\hline & Foot & $5(22.7)$ & $5(22.7)$ & 1 \\
\hline
\end{tabular}

Iranlan Rehab-1Itraton Journa 
Table 4. Outcome variable at baseline and post intervention for both groups

\begin{tabular}{llccccc}
\hline & & \multicolumn{2}{c}{ Mean(SD) } & & df & P \\
\cline { 3 - 5 } & & Pilates Group & Control Group & & \\
\hline \multirow{2}{*}{ FES-I (16-64 point) } & Pre-test & $32.9(5.6)$ & $33.7(4.2)$ & 42 & $P=0.6$ \\
& Post-test & $22.18(2.8)$ & $32.7(3.9)$ & 42 & $P<0.001$ \\
& & $P<0.001$ & $P<0.001$ & & \\
\hline
\end{tabular}

Mranlan Rehabolltutton Journal

and power can independently contribute towards increasing the Fear of Falling (FOF) [40]. Inherently, muscle strength is known to decrease after the age of 30 years. It has also been proposed that the best solution to improve or at least maintain it, is by exercising [41]. In sports, such as Tai Chi and Pilates, role of stabilizer muscles, moving muscles and retroactive muscles, keep shifting constantly and this shifting helps in improving muscle strength [42]. The information presented in the articles published by Irez et al. (2011), Kao et al. (2015) and Kamali et al. (2016) suggest that Pilates is also one of the best exercises that can help in increasing muscle strength [30, 35, 43].

After muscle strength, Loss of Balance is the next strongest risk factor responsible for FOF. It is known to be related to numerous other factors, like reduced rate of muscle response, strength and depth receptors caused due to aging $[44,45]$. Recent studies have shown that Pilates can help in increasing strength and postural stability. Furthermore, the basic principle behind Pilates exercise requires concentrating, coordinating and controlling body movements that are essentially the requirements of depth receptor stimulation. Hence, Pilates exercise is done by bearing one's own weight and focusing on the power center of the body which helps in improving postural stability and balance [46]. In addition, Kaesler et al. (2007) and Kamali et al.(2016) also indicated that Pilates can also be used for improving static and dynamic balance among the elderly $[34,47]$.

Conversely, Bird et al. (2012) reported no significant differences in static and dynamic balance between the intervention and control group of similar Pilates exercise based studies [26]. Such anomalous results may also be attributed to low sample size ( 32 individuals) and method of the study (cross-over). Meanwhile, it should also be considered that reduced muscle strength in lower extremity leads to position the center of gravity in front of the ankle joint that impairs the balance. On the other hand, improved muscle strength could shift the center of gravity to the ankle and improve balance [48].

In the present study, it was observed that adhering to the Pilates exercise principles, such as body center contraction, concentration and Precision during the training, helped in strengthening of the abdominal muscles, improvement of standing up state and postural aspects of the body. These factors altogether result in improved balance and decrease the FOF in elderly women. The results obtained in the present study were found to be in line with the results reported by some of the previous studies which indicated that community based interventions could improve the professional roles of nurses and help in addressing the changes caused due to aging $[49,50]$.

Hence, it is proposed that nurses, as the member of elderly healthcare team, can play effective roles in improving the overall health status of elderly women, especially in community based service settings [50]. The findings should be particularly emphasized in countries like Iran where the socio-cultural conditions do not approve of acceptation of sports by women due to the supposed limitations of women in accomplishing physical activities. The findings of the present study can help in creating

Table 5. Effect of pilates intervention on fear of falling with controlling age and the pretest scores

\begin{tabular}{cccccc}
\hline Source & Sum of Squares & Mean Square & F & P & Partial Eta Squared \\
\hline Age & 2159.66 & 4906.88 & 0.96 & 0.3 & 0.02 \\
Pretest scores & 361.4 & 361.4 & 130.8 & $<0.001$ & 0.76 \\
Group & 901.3 & 901.3 & 326.1 & $<0.001$ & 0.89 \\
\hline
\end{tabular}

Iranlan Rehabonlution Journal 
a new attitude towards the possible roles of exercising in decreasing the risk of falling and other related factors in the elderly population, especially elderly women. In addition, health care providers can use this study to formulate similar interventional strategies that can improve the quality of life of the elderly.

Having said all that, it should also be considered that the present study also had some major limitations, one among which is the possibility that the physical and psychological conditions of the participants during completion of questionnaires might have affected their responses. In addition, physiological differences among the selected individuals who participated in the study may have influenced the result. Most importantly these factors are out of the researcher's control and thus cannot be addressed.

\section{Conclusion}

Pilates exercise was found to be an effective solution that can reduce FOF in elderly women, which in turn may help in increasing their self-confidence for performing their daily activities without losing balance. It was found that these positive implications were due to the fact that adoption of the exercise program helped in improving muscle strength, flexibility and balance. Considering the importance of active and successful aging and role of physical activity and lifestyle on that, Pilates can be considered as a proper, non-violent, safe and medicine free intervention for the elderly women that must be taken into consideration by healthcare service providers, especially nurses.

\section{Acknowledgments}

This article is retrieved from the MSc. thesis of the first author's submitted to the University of Social Welfare and Rehabilitation Sciences. The research team would like to convey their sincere appreciation to the manager and staff of Kahrizak sanatorium day care center, Alborz Province, Ms. Alvani, the Pilates coach and all participants who kindly joined this research for their due support and patience throughout the study.

\section{Conflict of Interest}

The authors declared that there is no conflicts of interest regarding the publication of this article.

\section{References}

[1] Rubenstein LZ. Falls in older people: epidemiology, risk factors and strategies for prevention. Age and Ageing. 2006; 35(suppl_2):37-41. doi: 10.1093/ageing/afl084

[2] Stevens JA, Ballesteros MF, Mack KA, Rudd RA, DeCaro E, Adler G. Gender differences in seeking care for falls in the aged medicare population. American Journal of Preventive Medicine. 2012; 43(1):59-62. doi:10.1016/j.amepre.2012.03.008

[3] Van Schoor NM, Smit JH, Pluijm SM., Jonker C, Lips P. Different cognitive functions in relation to falls among older persons. Journal of Clinical Epidemiology. 2002; 55(9):855-62. doi: 10.1016/s0895-4356(02)00438-9

[4] Khajavi D, Jaberi Moghadam AA, Kazemnejad A. [Correlation between changes in balance and fall-related psychological and functional measures of men older adults after a combined training program (Persian)]. Motor Behavior. 2014; 17:55-72.

[5] Leung A, Chi I, Lou VW, Chan KS. Psychosocial risk factors associated with falls among Chinese community dwelling older adults in Hong Kong. Health \& social care in the community. 2010; 18(3):272-81. doi: 10.1111/j.1365-2524.2009.00900.x

[6] Mane A, Patil P, Sanjana T, Sriniwas T. Prevalence and correlates of fear of falling among elderly population in urban area of Karnataka, India. Journal of Mid-life Health. 2014; 5(3):150. doi: 10.4103/0976-7800.141224

[7] Oh E, Hong GRS, Lee S, Han S. Fear of falling and its predictors among community living older adults in Korea. Aging \& Mental Health. 2015; 21(4):369-78. doi: 10.1080/13607863.2015.1099034

[8] Tomita Y, Arima K, Kanagae M, Okabe T, Mizukami S, Nishimura $\mathrm{T}$, et al. Association of physical performance and pain with fear of falling among community-dwelling Japanese women aged 65 years and older. Medicine. 2015; 94(35):1449. doi: 10.1097/md.0000000000001449

[9] Donoghue OA, Cronin H, Savva GM, O'Regan C, Kenny RA. Effects of fear of falling and activity restriction on normal and dual task walking in community dwelling older adults. Gait \& Posture. 2013; 38(1):120-4. doi: 10.1016/j.gaitpost.2012.10.023

[10] Scheffer AC, Schuurmans MJ, van Dijk N, van der Hooft T, de Rooij SE. Fear of falling: Measurement strategy, prevalence, risk factors and consequences among older persons. Age and Ageing. 2008; 37(1):19-24. doi: 10.1093/ageing/ afm169

[11] Dukyoo Jung, Juhee Lee, Lee SM. A meta analysis of fear of falling treatment programs for the elderly. Western Journal of Nursing Research. 2008; 31(1):6-16. doi: $10.1177 / 0193945908320466$

[12] Pata RW, Lord K, Lamb J. The effect of Pilates based exercise on mobility, postural stability, and balance in order to decrease fall risk in older adults. Journal of Bodywork and Movement Therapies. 2014; 18(3):361-7. doi: 10.1016/j. jbmt.2013.11.002

[13] Ayoubi F, Launay CP, Annweiler C, Beauchet O. Fear of falling and gait variability in older adults: a systematic review and meta analysis. Journal of the American Medical Directors Association. 2015; 16(1):14-9. doi: 10.1016/j.jamda.2014.06.020 
[14] Center for Disease Control and Prevention. Important facts about falls [Internet]. 2015. Available from: https://www. cdc.gov/homeandrecreationalsafety/falls/adultfalls.html

[15] Pashaki NJ, Mohammadi F, Jafaraghaee F, Mehrdad N. Factors influencing the successful aging of Iranian old adult women. Iranian Red Crescent Medical Journal. 2015; 17(7). doi: 10.5812/ircmj.22451v2

[16] Mirabzadeh A, Forouzan AS, Mohammadi F, Dejman M, Eftekhari MB. How Iranian women conceptualize mental health: An explanatory model. Iranian Journal of Public Health. 2014; 43(3):342-8. PMCID: PMC4419172

[17] Mohammadi F, Eftekhari MB, Dejman M, Forouzan AS, Mirabzadeh A. Seeking comfort: Women mental health process in IR Iran: A grounded theory study. International Journal of Preventive Medicine. 2014; 5(2):217-23. PMCID: PMC3950746

[18] Chang HT, Chen HC, Chou P. Factors associated with fear of falling among community dwelling older adults in the Shih Pai study in Taiwan. PloS one. 2016; 11(3):e0150612. doi: 10.1371/journal.pone.0150612

[19] Brouwer BJ, Walker C, Rydahl SJ, Culham EG. Reducing fear of falling in seniors through education and activity programs: A randomized trial. Journal of the American Geriatrics Society. 2003; 51(6):829-34. doi: 10.1046/j.13652389.2003.51265.x

[20] Cameron ID, Stafford B, Cumming RG, Birks C, Kurrle SE, Lockwood K, et al. Hip protectors improve falls self efficacy. Age and Ageing. 2000; 29(1):57-62. doi: 10.1093/ageing/29.1.57

[21] Olsen C, Bergland A. The effect of exercise and education on fear of falling in elderly women with osteoporosis and a history of vertebral fracture: Results of a randomized controlled trial. Osteoporosis international. 2014; 25(8):2017-25. doi: $10.1007 /$ s00198-014-2724-3

[22] Arantes PM, Dias JMD, Fonseca FF, Oliveira AM, Oliveira MC, Pereira LS, et al. Effect of a program based on balance exercises on gait, functional mobility, fear of falling, and falls in prefrail older women: A randomized clinical trial. Topics in Geriatric Rehabilitation. 2015; 31(2):113-20. doi: 10.1097/ tgr.0000000000000056

[23] Kendrick D, Kumar A, Carpenter H, Zijlstra G, Skelton DA Cook JR, et al. Exercise for reducing fear of falling in older people living in the community. The Cochrane database of systematic reviews. 2014; 11:CD009848. doi: 10.1002/14651858. CD009848.pub2.

[24] Schmid AA, Van Puymbroeck M, Koceja DM. Effect of a 12-week yoga intervention on fear of falling and balance in older adults: A pilot study. Archives of Physical Medicine and Rehabilitation. 2010; 91(4):576-83.doi: 10.1016/j. apmr.2009.12.018

[25] Sungkarat S, Boripuntakul S, Chattipakorn N, Watcharasaksilp K, Lord SR. Effects of tai chi on cognition and fall risk in older adults with mild cognitive impairment: a randomized controlled trial. Journal of the American Geriatrics Society. 2016; 65(4):721-7. doi: 10.1111/jgs.14594

[26] Bird ML, Hill KD, Fell JW. A randomized controlled study investigating static and dynamic balance in older adults after training with Pilates. Archives of Physical Medicine and Rehabilitation. 2012; 93(1):43-9. doi: 10.1016/j.apmr.2011.08.005
[27] Yu W, An C, Kang H. Effects of resistance exercise using thera band on balance of elderly adults: A randomized controlled trial. Journal of Physical Therapy Science. 2013; 25(11):1471-3. doi: 10.1589/jpts.25.1471

[28] Di Lorenzo CE. Pilates: What is it? Should it be used in rehabilitation. Sports Health. 2011; 3(4):352-61. doi: $10.1177 / 1941738111410285$

[29] Menacho MO, Obara K, Conceição JS, Chitolina ML, Krantz DR, da Silva RA, et al. Electromyographic effect of mat pilates exercise on the back muscle activity of healthy adult females. Journal of Manipulative and Physiological Therapeutics. 2010; 33(9):672-8. doi: 10.1016/j.jmpt.2010.08.012

[30] Irez GB, Ozdemir RA, Evin R, Irez SG, Korkusuz F. Integrating Pilates exercise into an exercise program for $65+$ yearold women to reduce falls. J Sports Sci Med. 2011; 10(1):10511. PMCID: PMC3737905

[31] Segal NA, Hein J, Basford JR. The effects of pilates training on flexibility and body composition: An observational study. Archives of Physical Medicine and Rehabilitation. 2004; 85(12):1977-81. doi: 10.1016/j.apmr.2004.01.036

[32] Wells C, Kolt GS, Bialocerkowski A. Defining pilates exercise: A systematic review. Complementary Therapies in Medicine. 2012; 20(4):253-62. doi: 10.1016/j.ctim.2012.02.005

[33] Cruz Díaz D, Martínez Amat A, Manuel J, Casuso RA, de Guevara NML, Hita Contreras F. Effects of a six week pilates intervention on balance and fear of falling in women aged over 65 with chronic low back pain: A randomized controlled trial. Maturitas. 2015; 82(4):371-6. doi: 10.1016/j.maturitas.2015.07.022

[34] Kaesler D, Mellifont R, Kelly PS, Taaffe D. A novel balance exercise program for postural stability in older adults: A pilot study. Journal of Bodywork and Movement Therapies. 2007; 11(1):37-43. doi: 10.1016/j.jbmt.2006.05.003

[35] Kao YH, Liou TH, Huang YC, Tsai YW, Wang KM. Effects of a 12-week pilates course on lower limb muscle strength and trunk flexibility in women living in the community. Health care for Women International. 2015; 36(3):303-19. doi: 10.1080/07399332.2014.900062

[36] Shea S, Moriello G. Feasibility and outcomes of a classical Pilates program on lower extremity strength, posture, balance, gait, and quality of life in someone with impairments due to a stroke. Journal of Bodywork and Movement Therapies. 2014; 18(3):332-60. doi: 10.1016/j.jbmt.2013.11.017

[37] Yardley L, Beyer N, Hauer K, Kempen G, Piot Ziegler C, Todd C. Development and initial validation of the Falls Efficacy Scale-International (FES-I). Age and Ageing. 2005; 34(6):614-9. doi: 10.1093/ageing/afi196

[38] Khajavi D. [Validation and reliability of Persian version of Fall Efficacy Scale-International (FES-I) in community-dwelling older adults (Persian)]. Iranian Journal of Aging. 2013, 8(2):39-47

[39] Pérez VSC, Haas AN, Wolff SS. Analysis of activities in the daily lives of older adults exposed to the pilates method. Journal of Bodywork and Movement Therapies. 2014; 18(3):32631. doi: 10.1016/j.jbmt.2013.10.004

[40] Trombetti A, Reid K, Hars M, Herrmann F, Pasha E, Phillips E, et al. Age associated declines in muscle mass, strength, power, and physical performance: Impact on fear of falling 
and quality of life. Osteoporosis International. 2016; 27(2):46371. doi: $10.1007 / \mathrm{s} 00198-015-3236-5$

[41] Candeloro J, Caromano F. Effect of a hydrotherapy program on flexibility and muscle strength in elderly women. Brazilian Journal of Physical Therapy. 2007; 11(4):303-9. doi: 10.1590/S1413-35552007000400010

[42] Cheng TO. Tai Chi: The Chinese ancient wisdom of an ideal exercise for cardiac patients. International Journal of Cardiology. 2007; 117(3):293-5. doi: 10.1016/j.ijcard.2006.06.021

[43] Kamali A, Mahdavinejad R, Norouzi K. [The effect of selected pilates exercises on thigh muscle strength and depression in elderly women (Persian)]. Journal of Paramedical Science and Rehabilitation. 2016; 5(2):67-75.

[44] Rebbapragada A, Benchabane H, Wrana J, Celeste A, Attisano L. Myostatin signals through a transforming growth factor $\beta$-like signaling pathway to block adipogenesis. Molecular and Cellular Biology. 2003; 23(20):7230-42. doi: 10.1128/ mcb.23.20.7230-7242.2003

[45] Seadiabdoli S. [Investigating the relationship between strength, range of motion, the ratio of opposite muscles and balance in the ankle and knee joint with falling in the elderly man (Persian)] [MSc. thesis]. Tehran: Islamic Azad University, Central Tehran Branch 2012:72P.

[46] De Siqueira Rodrigues BG, Cader SA, Torres NVOB, de Oliveira EM, Dantas EHM. Pilates method in personal autonomy, static balance and quality of life of elderly females. Journal of Bodywork and Movement Therapies. 2010; 14(2):195202. doi: 10.1016/j.jbmt.2009.12.005

[47] Kamali A, Mahdavinejad R, Norouzi K. [The effect of a period of selected pilates exercise on rang of motion and balance of elderly women (Persian)]. Journal of Sport Rehabilitation. 2014; 2(4):11-22.

[48] Ebrahimi Takamjani E, Noorbakhsh MR, Basiri SH. [Assessing the influence of sensory information on controling standing balance in different age groups (Persian)]. Razi Journal of Medical Sciences. 2000; 7(21):171-5.

[49] Jokar Z, Mohammadi F, Khankeh HR, Fallah Tafti S. [Effect of Home-based Pulmonary Rehabilitation on Fatigue in Patients with COPD (Persian)]. Journal of Hayat. 2013; 18(5):6472 .

[50] Mohammadi F, Jowkar Z, Khankeh HR, Fallah Tafti S. Effect of home based nursing pulmonary rehabilitation on patients with chronic obstructive pulmonary disease: A randomised clinical trial. British Journal of Community Nursing. 2013; 18(8). doi: 10.12968/bjen.2013.18.8.398 